\title{
Three 'Delays' as a Framework for Critical Analysis of Maternal Near Miss and Maternal Mortality
}

\author{
Saira Yunus, Shahnaz Kauser, Shazia Ali
}

\begin{abstract}
Objective: The aim of the study was to assess the magnitude and causes of three delays and their possible implications for safe motherhood.

Methods: The cross-sectional prospective study was carried out over a period of 1 year from J anuary to December 2010. All patients who fulfill the WHO criteria for maternal near miss and all cases of maternal death during this period were included in the study. The various factors responsible for the delays in accessing obstetrics care facilities at all the three levels were analyzed.
\end{abstract}

Results: During 1 year period there were 10,553 emergency admissions in labor room and there were 4538 deliveries, out of these 123 patients who fulfilled the WHO criteria for near miss were included in the study. $83 \%$ of patients (102) reported first delay in seeking care and the most common reason for delay was inability to judge the graveness of situation. After initial care there was a delay in reaching a facility with comprehensive obstetric care in $62 \%$ of cases (76 patients) and this delay was of around 6 to 8 hours. Once the patients reached J innah Hospital there was a delay in about 15 (12\%) patients. There were 13 maternal deaths during this period of 1 year and there was a delay both at seeking initial care and referral by the initial care providers.

Conclusion: Delay in deciding to seek care (1st delay) was the major factors responsible for high maternal mortality and morbidity. So the role of community actors such as mothers in law, husbands, local healers and pharmacies and increased access to properly trained birth attendants need to be addressed if delays in reaching health facilities are to be shortened.

Keywords: Maternal mortality, Maternal near miss, Maternal mortality ratio (MMR), Hemorrhage, Eclampsia.

How to cite this article: Y unus S, Kauser S, Ali S. Three 'Delays' as a Framework for Critical Analysis of Maternal Near Miss and Maternal Mortality. J South Asian Feder Obst Gynae 2013;5(2):57-59.

\section{Source of support $\mathrm{Nil}$}

Conflict of interest: None declared

\section{INTRODUCTION}

Pregnancy is the normal healthy event in the reproductive life of women, yet this life affirming process may cause the risk of death and disability for many women.

$M$ aternal death in the developed countries are almost on decline. However, the poor women of the developing countries are yet deprived of their fundamental right to live. Globally every year an estimated 5,29,000 maternal deaths occur due to pregnancy related preventable causes like hemorrhage, hypertensive disorders, sepsis, obstructed labor and unsafe abortions. The world figure of M M R is estimated to be $400 /$ 100,000 live births but it is not uniformly distributed. The M M R is highest in Africa (830) followed by A sia (330), Oceania (240), Latin A merica and Caribbean (190) and developed countries (20). ${ }^{1}$

Pakistan is similar to many other developing countries in having an unacceptably high maternal mortality. A ccording to WHO and UNICEF estimates, maternal mortal ity ratio (M MR) of Pakistan is around 340/100,000 live births. ${ }^{2}$ Population based study done in early 1990s indicate M M R ranging from 281/ 100,000 live births in Karachi to $673 / 100,000$ live births in Baluchistan. ${ }^{3}$

When it comes to preventing maternal mortality and disability, timing is critical: Although postnatal hemorrhage can kill a woman in less than 2 hours, most other complications have a window of 12 hours or more during which to obtain life-saving emergency care. The 'three delays' model is a useful yardstick to manage obstetric complication, and to design programs to prevent maternal death or injury.

The three delays are as follows:

- Delay in deciding to seek care

- Delay in reaching appropriate care

- Delay in receiving care at health facility.

The first two relate directly to the issue of access to care including family pressure to give birth at home because of social or community pressure or owing to inadequate funds for transportation. Reaching a heal th facility does not necessarily mean the end of the journey as the nearest facility may not be equipped to treat the condition or even administer essential first aid so patients are referred to another facility that is better equipped. ${ }^{4}$ The third relates to inadequacies within the heal th care system itself. This could be lack of properly trained personal, transfusion equipment and other infrastructural inadequacies. L ate or wrong diagnosis and incorrect action by the staff are other factors that contribute to delays in the timely provision of needed care. U nless the three del ays are addressed, no safe motherhood programs can succeed. ${ }^{5}$

\section{RESULTS}

During 1 year period there were 10,553 emergency admissions in labor room and there were 4538 number of deliveries.

A total of 123 patients were admitted through emergency in our unit who fulfilled the WHO criteria for near miss. There were 13 maternal deaths during this 1 year. M ost of the patients $81 \%$ were in a state of shock at the time of presentation. The underlying cause of shock was commonly vaginal bleeding either due to $\mathrm{APH}, \mathrm{PPH}$, ruptured uterus or ruptured ectopic pregnancy. 
Out of 123 patients 102 (83\%) reported first delay in seeking care and the most common reason for delay was inability to judge the graveness of situation. In most of the cases there were multiple factors responsible for delay in seeking care as shown in Table 1 (as there was more than one factor responsible for delay in each patient so the total number in this table exceed the actual no of patients enrolled in study).

Time taken by family in deciding to seek care was on average 4 to 7 days and the first care provider was traditional birth attendant in most of the cases (51\%) as shown in Table 2 .

A fter intial care there was a delay in reaching a facility with comprehensive obstetic care in $62 \%$ ( 76 patients) and this delay was usually of around 6 to 8 hours. The commonest reasons for second delay were delay in referral as shown in Table 3 (as there was more than one factor responsible for delay in each patient so the total number in this table exceed the actual no of patients enrolled in study).

Once the patients reached the Innah Hospital there was a delay in about $12 \%$ of patients. The commonest cause of delay to proceed for any life saving surgical intervention was the nonavailability of blood and blood components. Other causes were delay in receiving reports of requested investigations, non availability of attendants, theater table not availabe and lack of availability of bed in ICU in patiens requiring ventilatory support (Table 4).

There were 13 total deaths and 12 out of these 13 patients presented in critical condition and there was a delay both at seeking initial care and referral by the initial care providers.

\section{Table 1: Causes of first delay}

\begin{tabular}{ll}
\hline Inability to judge the graveness & 92 \\
Waiting for results of informal treatment & 88 \\
Financial problem & 66 \\
Deciding person not available & 32 \\
Transport problem & 27 \\
Others & 16 \\
\hline
\end{tabular}

\begin{tabular}{lr}
\multicolumn{2}{c}{ Table 2: First care provider $(n=123)$} \\
\hline Traditional birth attendant & $51 \%$ \\
Local clinic/hospital & $36 \%$ \\
Family member & $13 \%$ \\
\hline
\end{tabular}

Table 3: Factors responsible for second delay

Delay in referral 42

Fear of cost and distance $\quad 22$

Not sure where to go

Transport not available 11

Deciding accompanying person not available 5

Others
Table 4: Factors responsible for third delay

Nonavailability of blood and blood components

Delay in getting reports of required investigations

Delay due to nonavailability of attendants

Nonavailability of ventilatory support

Failure to provide resuscitation on arrival

Delay in surgery due to nonavailability of theater

Delay in decision
Table 5: Causes of maternal mortality $(n=13)$

Hemorrhage

Hypertension and its complication

Sepsis

Others ( $E$ isenmenger syndrome)

The cumulative M M R for the year 2010 of our unit is 286.4/ 100,000 . Direct causes accounted for $92 \%$ of maternal deaths. A mong them hemorrhage was the leading cause of death $(38 \%)$ as shown in Table 5.

\section{DISCUSSION}

Death of mother is a tragic event. In practical life, it has a severe impact on the family, community and eventually the nation. The young surviving children left motherless are unable to cope with daily living and are at an increased risk of death. Reduction of maternal mortality is an important MDG especially in low income countries, where one in 16 women dies of pregnancy related complications. M M R ratio varies throughout different countries of the world. In sub- Saharan A frica, M M R reported in 2000 was 1000 live births, almost twice that of A sia four times higher than in L atin A merica and Caribbean and nearly fifty times higher than in industrialized countries.

The pathway to maternal deaths has been related to the three phase delays. It was difficult to exactly relate the cause of death merely due to the individual delay, since in most of the patients a combination of events was observed. M aximum patients in our study $(83 \%)$ had first delay in seeking care for an average of 4 to 7 days. The results of our study are comparable to the study conducted in rural $B$ angladesh to assess perceived delay in health seeking for episodes of serious illness and its implications for safe motherhood. The study showed that in $69 \%$ of patients there was a delay in deciding to seek care and the time required to make a decision to seek care was on average 3 to 5 days. The study reported that inability to judge the graveness of situation was the commonest reason for delay $(45 \%) .{ }^{6} \mathrm{M}$ ore than one factor was responsible for the delay in seeking care, inability to judge the graveness of situation and waiting for the results of informal treatment were the commonest $(80-86 \%)$. A ccording to our study traditional birth attendant was the first care provider in about $51 \%$ in contrast to a study conducted at Liaquat U niversity Hospital, Hyderabad where doctor was the first care provider in most of the cases $(46.5 \%)$. $^{7}$

In our study second delay in seeking comprehensive obstetric care facility was observed in $62 \%$ (76) patients. The commonest reason for second delay was delay in referral by the first care providers. M ajority were brought by own transport without proper referral notes. The likely need for surgery and need of arrangement of blood was even not explained to the patients and their attendants and this led to further delay at tertiary care. Same factors have been highlighted in UNICEF's report from India. ${ }^{8}$ Hence, there is a need to create a good communication and rapid transport networks among the peripheral and central health facilities. The flaws in management at the health centers are to be addressed by non- 
Three 'Delays' as a Framework for Critical Analysis of Maternal Near Miss and Maternal Mortality

condemned policy. The adequacy of quality health services should be continuously monitored both at private and government sectors.

On reaching J innah H ospital the commonest cause of delay to proceed for a life saving surgical intervention was the nonavailability of blood and blood components and del ay in getting repots of required investigations. A dvancements for provision of individual blood components should be made since whole blood transfusions are no more practiced world wide and such provision can avoid the mortalities related to hemorrhage. N onavailability of ventilatory support and theater table was an other common reason for delay at tertiary care, so there is dire need to extend the intensive care and surgical facilities to meet the heavy workload and this should be a top priority.

There were 13 maternal deaths in our unit during the study period. Direct causes accounted for $92 \%$ of maternal deaths. A mong the direct causes hemorrhage continues to be a major contributor of maternal mortality (38\%). In Pakistan, the reported figures vary from 21 to $34 \% .{ }^{9}$ Good nutrition and prompt obstetrics care has reduced the maternal mortality related to hemorrhage in development countries, but much need to be done to prevent maternal deaths secondary to hemorrhage in devel oping countries like Pakistan. Good antenatal care with built-up of iron stores can increase the tolerability to shock. Hypertensive disorders and sepsis were the other main contributors to maternal mortality. As $95 \%$ of the patients who presented in critical condition were unbooked with none or inadequate antenatal care so prompt antenatal care is mandatory for prevention of obstetric mishaps. Early recognition and treatment of PIH can prevent the lethal maternal complications associated with hypertensive disorders. Sepsis contributed to three maternal deaths. A septic techniques and judicious use of antibiotics have also reduced the number of deaths in the developed countries. ${ }^{10}$ Ensuring hygienic conditions at birth, prompt detection of infection and proper use of antibiotics could have prevented these deaths.

\section{CONCLUSION}

Delay in deciding to seek care (1st delay) was the major factors responsible for high maternal mortality and morbidity. $M$ ajor obstacle to seeking care was a limited capacity to recognize danger signs; the need to watch and wait; and an overwhelming preference to treat illness within the community. Safe motherhood and new born care programs in communities, must address both community and health facility care to have an impact on morbidity and mortality. The role of community actors such as mothers in law, husbands, local healers and pharmacies and increased access to properly trained birth attendants need to be addressed if delays in reaching health facilities are to be shortened.

\section{REFERENCES}

1. World Health Organisation. Maternal M ortality in 2000: Estimates developed by WHO, UNICEF and UNFPA. (online) 2009 (cited $2009 \mathrm{M}$ arch 12). A vailable from URL: www.who.int 2000.

2. W omen's health in Pakistan. Fact sheets prepared for Pakistan N ational forum on Women's health. WHO 1997 N ov;14:3-5.

3. Fikree FF, M idhat F, Sadruddin S, B erendes HW. M aternal mortal ity in different Pakistani sites: R atios, clinical causes and determinants. A cta Obstet Gynecol Scand 1997;76:637-45.

4. Thaddeus $S, M$ aine $D$. Too Far to W alk: M aternal M ortality in Context, Social Science and M edicine 1994;38(8):1091-1110.

5. UNFPA: No Woman Should Die Giving Life: http:// www.unfpa.org/safemotherhood.

6. Killewol J, A nwar I, B ashir I, Y unus M, Chakraborty J. Percieved delay in healthcare-seeking for episodes of serious illness and its implications for safe motherhood interventions in rural B angladesh. J H ealth Popul N utr 2006 Dec;24(4):403-12.

7. Hassan N, Scrichand P, Zaheen Z. One year analysis of maternal deaths at L iaquat U niversity H ospital Hyderabad, J L U M HS SepDec 2007.

8. Bakshi R. Maternal mortality-a woman dies every 5 minutes in childbirth in India. M arch 2008. A vailable at: http:www. unicef.org/lndia/heal th1341.html. A ccessed on 280 ctober 2006.

9. B egum $\mathrm{S}, \mathrm{N}$ issa $\mathrm{A}, \mathrm{B}$ egum I. A nalysis of maternal mortality at tertiary care hospital to determine causes and preventable factors. J A yub M ed Coll A bbotabad 2003;15(2):49-52.

10. Loudon I. M aternal mortality 1880-1950: Some regional and international comparisons. Soc H ist M ed 1988;1:183-228.

\section{ABOUT THE AUTHORS}

\section{Saira Yunus (Corresponding Author)}

A ssistant Professor, Gyne U nit-I, Postgraduate M edical Institute/L GH, Lahore, Pakistan, Phone: 03334339920,e-mail: sairaymian@ gmail.com

\section{Shahnaz Kauser}

Assistant Professor, Gyne Unit-I, Jinnah Hospital/A llama Iqbal Medical College, Lahore, Pakistan

\section{Shazia Ali}

Senior R egistrar, Gyne U nit-I, Jinnah Hospital/A llama Iqbal M edical College, Lahore, Pakistan 